\title{
Construction of Course Security System for Training Platform of Talents of Energy-Conservation- Emissions-Reduction
}

\author{
Xingjia Liu \\ Department of Energy and Power Engineering, Harbin University of Science and Technology, Harbin, \\ China
}

xj3333333@sina.com

Keywords: Energy-saving-emission-reduction talent; Energy professional training platform; Characteristics training; Talent competitiveness; Sustainable development

\begin{abstract}
In allusion to the importance, the necessity and the urgency of the demand for talents energy-conservation-emissions-reduction, the purpose of this paper is seeking how to build professional talent training platform and how to solve corresponding problems; The paper analyzed the opportunities and challenges of energy specialty training higher professional talent in low-carbon economy times; On the analysis of the importance and difficulty of wide caliber characteristic professional talent training for enhancing the talent cultivation competitiveness, puts forward the suggestion what question should considered in construction of the course security system for personnel training and what ways and means should be solved. The results can help to solve how to build the course security platform of energy professional and other ones.
\end{abstract}

\section{Introduction}

Energy is the basis and important advancement of human social development. With the acceleration of national economic development, energy consumption is expanding rapidly. Energy shortage and environmental pollution caused by the use of energy are increasingly serious. It has seriously threatened the economic development and even the human survival [1]. How to solve these problems is imminent. On a global scale, through the energy conservation and emissions reduction, economic and social sustainable development is promoted.

However, promoting energy-conservation- emissions-reduction is a long way to go, need a large number of high-level technical personnel with relevant concept and knowledge structure. As a personnel training important basis of institutions of higher learning must shoulder the important task to develop low carbon economy. And as an energy specialty is close relationship with the low carbon economy in professional nature, energy-conservation- emissions-reduction, its talent cultivation should be in one of the leading enterprises.

On the other hand, under the new situation, new and higher requirements on the talents are constantly put forward in the economic and social development. The institutions of higher learning in the talent market face more and more competitive. They must adjust the professional structure, must innovate the training mode in the talent market competition [1], so as to cultivate students to become strong adaptability and self-regulation, to be able to do a variety of job. Only in this way, the students can be accepted by the market. To achieve this goal, a characteristic and competitive professional personnel training platform and its course security system must be build.

In this article, the energy-conservation-emissions-reduction talent market prospect and demand as well as the strategy of talent training in our country are analyzed from the national economic development from the traditional economic transition to a low-carbon economy. According to the nature and characteristics of energy specialty, construction of the talent cultivation platform and its course security system adapting to energy-saving-emission-reduction has been explored and practiced. The results are hopeful to be applied to cultivation of the applied interdisciplinary talents who are both with the concept and knowledge structure of energy-conservation-emissions-reduction, and with a 
wide range of adaptability and distinct features. The results also have reference significance to the relevant professional talent training.

\section{Opportunities and Challenges of Talent Cultivation in Energy Specialty under Low-carbon Economy}

An important way of low-carbon economy development is energy-conservation-emissions- reduction. To achieve this development mode requires innovation which includes the concept of policy, technology and concept. The innovation must have the relevant personnel, especially high-level talents. In essence, the economic competition is the talent competition. In the around world, who can cultivate a large number of outstanding talents of low-carbon more faster and can more fully play their role, who can grab the commanding heights of the low carbon economy development and can better and faster develop low-carbon economy [2] [3].

China want to achieve rapid and sustainable development under the background of the low-carbon economy, must cultivate a large number of excellent innovative talents with concept and knowledge structure of energy-conservation-emissions-reduction [4]. This is the effective guarantee for the sustainable development of countries in economic transition period [5].The relationship of energy specialty with energy-conservation-emissions-reduction is very close. This situation is a rare opportunity and austere challenges [6]. the opportunity is needs of a large number of relevant personnel in economic transition period, and the student's employment space is larger; Challenge is talents needed by society are diversified and High demand situation, as well as balanceless and lagging of economic transformation. and development. These will be detrimental to the student employment.

Not only that, because of the restriction of the economic development speed and other factors, the transformation of from traditional economy to a low-carbon economy will not happen overnight. In a long time, there is the imbalance of higher education personnel training and social needs. The employment contradiction increasingly highlighted [7]. Especially, there is a considerable distance between the culturing high-quality talents with thinking and knowledge structure of energy-savingemission -reduction and low-carbon economy development.

For the training of energy professional talents under the new situation, the determination of training objective and accurate positioning are very important. On this basis, we must construct the corresponding talent cultivation platform which should be able to cultivate the talents with the concept and knowledge structure of energy-conservation-emissions-reduction. The establishment of characteristic curriculum system is an important part to build the professional personnel training platform and to realize training target. With such a talent training platform, we can seize the opportunities brought by the economic transformation, and effectively cope with the challenge faced.

\section{Construction of Competitive Characteristic Curriculum System to Adapt to Energy-saving -emission-reduction}

The basic guarantee to achieve the target of talent cultivation in energy specialty is to build a distinctive talent training course system which is adapt to energy-conservation-emissions-reduction talent training and should have the following characteristics [8, 9]:

The professional caliber is wide, to enhance the students' ability to adapt extensively, and to expand their employment space; the characteristics are distinct, to adapt to the training goal and positioning of the school and to enhance competitiveness of cultivated students in the talent market; the cultivated students have a comparatively systematic concept and knowledge structure of energy-conservation-emissions- reduction, to make cultivated students have a certain superiority in talent market and low-carbon economy.

The importance of wide professional caliber talent cultivation has been broad consensus. The professional directory adjustment experienced a process of constantly expanding professional caliber. For example, today's energy and power-engineering specialty is made up of the original more professional. This adjustment is in order to meet the requirement of economic development in the 
talent market, in order to be coordinated with the popularization of higher education personnel training. But, the Wide caliber training personnel of should be not same, according to the school's own characteristics and advantages for positioning.

For high level key institutions of higher learning, its widened professional caliber should be larger. In such schools, the advantage of wide caliber specialty in the undergraduate stage has the following two aspects: that wide professional caliber can lay a good foundation for students into graduate student period; that it can broaden wider employment space for their students to their high-level reputation advantage.

For the general institutions of higher learning, its widened professional caliber should be appropriately smaller. They should consider not only the favorable factors that the professional caliber to be expanded can increase job opportunities, but also the unfavorable factors of the competition in colleges and universities. Therefore, this kind of school should be in the appropriate extension of professional caliber and at the same time, can't ignore the problem of professional counterparts. They should attach great importance to the professional knowledge of applied education, to facilitate graduate employment work and to enhance their competitiveness in the talent market [8].

What the above consideration Shows that the establishment of the professional personnel training platform should be from the following several aspects.

Broadening the Professional Caliber and Insisting Features should Same Considered to Establish Professional Personnel Training Platform. Why to widen specialty caliber is In order to expand students' knowledge Lay the foundation for compound talents cultivation, and increase their chances of employment. Why to adhere to the professional characteristics talents cultivation is in order to highlight its advantages, and to enhance the student's ability to participate in social competition.

To establish professional training platform effectively broadening the professional caliber, the corresponding curriculum system as a guarantee must be created. The curriculum system should meet the basic requirement which covers the content of original various professional. In terms of course selection and Settings, different colleges and universities should set out their own curriculum system According to their conditions, historical accumulation, features and advantage, etc.; On the selection of the course content, they can't combine the related contents of original various professional to do a simple piece together, there should be a leap in nature.

According to the requirement, establishment and operation of the professional personnel training platform and its course system is very difficult. In other to solve this difficult problem, the professional personnel training platform was established in curriculum system from the following several aspects.

A summary of each professional direction is the basis of extending professional knowledge, it covers various professional directions under large professional. Through studing this course, students can summarily understand and macroscopicly grasp the relevant knowledge of various professional directions under large professional to lay the foundation for learning subsequent courses.

Course content should mainly include the mutual content of the each professional direction and theoretical basis in the large professional platform. The course contents should broaden the professional and lay the foundation for learning the subsequent course, provide security knowledge for jobs. At the same time, the course should reflect the characteristics of professional training platform as much as possible.

Energy is the foundation of human survival and social development. Development low-carbon economy and implementation of energy-conservation-emissions-reduction presented the characteristics of the long-term and arduousness. The double consciousness of energy conservation and environmental protection must first be established in the minds of the students, and then the relevant knowledge structure of engaging in the work of energy-conservation-emissions-reduction must be grasped, to lay the foundation for engaging in the work in the field of low carbon economy. In order to achieve this goal, the curriculum system built should be able to guide the student to grasp the main line of energy utilization, and the two aspects Along with energy use: Energy-shortages and environmental-pollution. 
Establishing and Perfecting Professional Direction Curriculum System to Highlight the Characteristics. In order to meet the low carbon energy related one direction talent demand, professional direction course module should be established, so that together with the whole course system to form a more perfect curriculum system, in order to lay the foundation of cultivating applied talents, make the trained students to deeply grasp the direction of the system of the professional knowledge, obtain competitive advantage. We will further improve the characteristics of running a school.

The relevant courses in the energy field are set up, for students to take. On course selection, the courses should give full consideration to help the students form the concept and the knowledge structure of energy-conservation- emissions-reduction. The students are free to decide the elective subjects according to their interests and career planning, so as to both further improve the professional knowledge system of energy-conservation-emissions-reduction, and to be conducive to students' personality development.

To Strengthen Practical Teaching, Cultivate Students' Innovation Ability, Help Theory Teaching Effect. Practical teaching link has a great effect in the wide caliber talents cultivation of energy-saving-emission-reduction. Through the practical teaching, students' ability and quality can get a larger increase. In the process of making the training plan, to increase practice teaching hours and content are very necessary. Practical teaching activities can not only increase the depth students' understanding knowledge, but also can greatly improve the ability of solving practical problems. Under the condition of professional caliber broadened, this practical teaching can help the theory course teaching effect, and can help to solve the difficult problem how to improve teaching effect after the professional caliber widened. Therefore, the practical teaching and the theory teaching are complementary to each other. Practical teaching course system has a great and irreplaceable role in the cultivation of the student application ability and innovation ability and in the supporting of theory teaching.

Connecting Each Other and Complement Each Other in Curriculum System. The curriculum system which meets the talent training of energy-requirement- emissions-reduction must be a complete and scientific system. It is an important foundation of construction of personnel training platform. The education reform in institutions of higher learning is to realize transformation from the traditional pure knowledge education mode, to not only to impart knowledge to students, and to cultivate their ability and improve their quality. In order to achieve this goal, a complete scientific curriculum system will be established. The development and the survival of colleges and universities must be with characteristic.

The prominent problems are how to scientifically include concept and knowledge structure of energy-conservation-emissions-reduction and how to solve the contradiction between the specialty broadness and raising application ability. Within the limited class hour, that everything is very good is impossible. But the education reform not only can't reduce the quality of teaching, but also further improve the ability and quality of the personnel training. In order to effectively solve this problem, multi-dimensional integration of contents of teaching is very important, to make each link in the curriculum system be more closely, achieve mastery through a comprehensive study with each other, complement each other.

\section{Summary}

The sustainable development in china's economy must go the path of energy-conservationemissions-reduction. This is the only way for building the society of energy saving and environmentally friendly, is a global revolution in the value idea, the mode of production and life style. In low-carbon economy, energy-conservation-emissions-reduction talents exists two contradictions: a problem is lack of talents in this field, causing the unbalance of supply and demand; another problem is that necessary industry adjustment for energy-conservation-emissions-reduction may shut down part of the industry, and appear structural unemployment phenomenon. Low carbon economy put forward to new and higher requirements to colleges and universities. There are opportunities and challenges in 
the talent market at the same time. Under the background of popularization of higher education [10], difficult employment problem will exist for a long time. In this situation, the personnel training mode in the institutions of higher learning must form their own characteristics and advantages, to build a distinctive talent training platform and the corresponding curriculum system.

This is an important basis and a guarantee to improve the competitiveness of the professional personnel training. Of course, such course system will have a lot of difficulties in the process of operation. Its application and improving effect still need to do a lot of research work. The specialty of energy and power engineering in our school has made some beneficial attempt and exploration in this area. We have reason to believe that, with the deepening reform of higher education, and scientific operation mechanism will be established on the basis of perfecting. Improved the characteristic of personnel training platform and its curriculum system must be able to play a huge role in talents cultivation, and to contribute to the implementation of the talent cultivation targets for energy-conservation -emissions -reduction.

\section{Acknowledgement}

This work was supported by Heilongjiang Association of Higher Education (HGJXH B1110521). To express gratitude to them, at one time, to give thanks to other colleagues of our Department of Energy and Power Engineering who give us help.

\section{References}

[1] J. Liang, H.Q .Yin, J.X. Guo and F.M .Liao: Proceedings of the 2nd China Energy Scientist Forum (Xuzhou, Oct.2010), Vol.1-3(2010), p. 891.

[2] Y. Fu, Y.H. Ma, Y.J. Liu, W.Y. Niu: China Population (Resources and Environment), (2008), No.3, p. 14.

[3] J.R. Li: Proceedings of the 2nd China Energy Scientist Forum (Xuzhou, Oct.2010), Vol.1 (2010), p.835.

[4] R. Sun, J. Wu: Chinese Talents, (2013), No.19, p.54.

[5] X.D. Mao and S.J. Ao: Proceedings of the 2nd China Energy Scientist Forum (Xuzhou,

[6] J.R Li: Proceedings of the 2nd China Energy Scientist Forum (Xuzhou, Oct.2010), Vol.1-3(2010), p.835.

[7] Z. Wei and C. J. Deng: Journal of Higher Education in Science \& Technology, Vol.29, (2010), No.1, p. 1.

[8] J.W.Wu: Urban Construction Theory Research, (2015), No. 20.

[9] Z. F. Dong: Road to Success, (2015), No.15, p.30.

[10]X. L. Yang: Journal of Higher Education in Science \& Technology, Vol.29 (2010), No.6, p.8. 